Dementia

and Geriatric

Cognitive Disorders
Dement Geriatr Cogn Disord 2013;35:34-50

DOI: $10.1159 / 000345523$

Accepted: October 31, 2012

Published online: January 9, 2013
(C) 2013 S. Karger AG, Basel

$1420-8008 / 13 / 0352-0034 \$ 38.00 / 0$

www.karger.com/dem

\title{
Patterns of Brain Atrophy in Clinical Variants of Frontotemporal Lobar Degeneration
}

\author{
Po H. Lu ${ }^{a}$ Mario F. Mendez ${ }^{a, d} \quad$ Grace J. Lee ${ }^{a} \quad$ Alex D. Leow ${ }^{b, g, e}$
} Hyun-Woo Lee $^{k}$ Jill Shapira ${ }^{a}$ Elvira Jimenez ${ }^{a, d}$ Bradley B. Boeve ${ }^{h}$ Richard J. Caselli ${ }^{i}$ Neill R. Graff-Radfordj Clifford R. Jack ${ }^{\text {h }}$ Joel H. Kramer ${ }^{f}$ Bruce L. Miller $^{f}$ George Bartzokis ${ }^{b, c}$ Paul M. Thompson ${ }^{a, b}$ David S. Knopman ${ }^{\text {h }}$

\footnotetext{
${ }^{a}$ Department of Neurology, ${ }^{b}$ Laboratory of NeuroImaging, and ${ }^{\mathrm{C}}$ Department of Psychiatry and Biobehavioral Sciences, David Geffen School of Medicine at UCLA, and ${ }^{d}$ Greater Los Angeles VA Healthcare System, Neurobehavior Unit, Los Angeles, Calif., e Community Psychiatry Associates, Sacramento, Calif., ${ }^{f}$ Department of Neurology, University of California, San Francisco, Calif., gDepartments of Psychiatry and Bioengineering, University of Illinois, Chicago, Ill., hDepartment of Neurology, Mayo Clinic, Rochester, Minn., iDepartment of Neurology, Mayo Clinic, Scottsdale, Ariz., and 'Department of Neurology, Mayo Clinic, Jacksonville, Fla., USA;

kDepartment of Physics, McGill University, Montreal, Que., Canada
}

\section{Key Words}

Frontotemporal dementia $\cdot$ Primary progressive aphasia $\cdot$ Longitudinal study $\cdot$ Magnetic resonance imaging $\cdot$ Tensor-based morphometry $\cdot$ White matter

\begin{abstract}
Background/Aims: The clinical syndromes of frontotemporal lobar degeneration include behavioral variant frontotemporal dementia (bvFTD) and semantic (SV-PPA) and nonfluent variants (NF-PPA) of primary progressive aphasia. Using magnetic resonance imaging (MRI), tensor-based morphometry (TBM) was used to determine distinct patterns of atrophy between these three clinical groups. Methods: Twenty-seven participants diagnosed with bvFTD, 16 with SV-PPA, and 19 with NF-PPA received baseline and follow-up MRI scans approximately 1 year apart. TBM was used to create three-dimensional Jacobian maps of local brain atrophy rates for individual subjects. Results: Regional analyses were performed on the three-dimensional maps and direct comparisons between groups (corrected for multiple comparisons using permutation tests) revealed significantly greater frontal lobe and frontal white matter
\end{abstract}

This data was presented in part at the 7th annual meeting of the International Conference for Frontotemporal Dementia, Indianapolis, Ind., USA. 
atrophy in the bvFTD relative to the SV-PPA group $(p<0.005)$. The SV-PPA subjects exhibited significantly greater atrophy than the bvFTD in the fusiform gyrus $(p=0.007)$. The NF-PPA group showed significantly more atrophy in the parietal lobes relative to both bvFTD and SVPPA groups $(p<0.05)$. Percent volume change in ventromedial prefrontal cortex was significantly associated with baseline behavioral symptomatology. Conclusion: The bvFTD, SV-PPA, and NF-PPA groups displayed distinct patterns of progressive atrophy over a 1-year period that correspond well to the behavioral disturbances characteristic of the clinical syndromes. More specifically, the bvFTD group showed significant white matter contraction and presence of behavioral symptoms at baseline predicted significant volume loss of the ventromedial prefrontal cortex.

Copyright $(2013$ S. Karger AG, Basel

\section{Introduction}

The clinical syndromes of frontotemporal lobar degeneration (FTLD) include progressive personality and behavioral alterations (behavioral variant frontotemporal dementia, bvFTD) and/or language-predominant disorders [1]. Of the language variants of FTLD, the semantic variant of primary progressive aphasia (SV-PPA) involves severe loss of meaning for both verbal and nonverbal concepts resulting in impaired naming and word comprehension in the context of fluent, effortless speech output. Nonfluent/agrammatic variant of primary progressive aphasia (NF-PPA) is a disorder of expressive language characterized by hesitant and effortful speech production, phonologic and grammatical errors, and difficulties in word retrieval with relative preservation of comprehension [2].

In addition to having distinct clinical features, these three syndromes have also been associated with different regions of corresponding brain changes. At autopsy, the brains of patients with bvFTD show marked bilateral atrophy of the frontal and temporal lobes, most severely in the ventromedial regions of the orbitofrontal cortex, the anterior insula, and the anterior temporal regions, with relative preservation of posterior gyri $[3,4]$; asymmetric changes can also be observed. Atrophy patterns of SV-PPA at postmortem have been meticulously documented, emphasizing the involvement of the temporal pole and perirhinal cortex [5, 6]; atrophy of the lateral and ventral surfaces of the temporal lobes as well as the anterior hippocampus and amygdala [7, 8] have also been observed. NF-PPA is associated with anterior perisylvian atrophy involving inferior, opercular and insular portions of the left frontal lobe [7-9].

Several magnetic resonance imaging (MRI) studies have attempted to map in vivo brain structural changes associated with FTLD. Cross-sectional imaging studies have revealed significant atrophy of the frontal lobes in patients with bvFTD, affecting both gray and white matter [10]. A recent meta-analysis indicated gray matter changes in the frontal-striatallimbic regions associated with bvFTD [11]. Left temporal lobe atrophy, most strongly toward the temporal pole, was demonstrated in SV-PPA patients [12], while Mion et al. [13] reported on the involvement of the anterior fusiform gyrus in this population. In longitudinal studies, Chan et al. [14] documented annual whole brain volume loss of $3.7 \%$ per year with predominant anterior frontal and temporal lobe atrophy. Whitwell et al. [15] found increased frontal, temporal, and parietal atrophy in a combined FTLD population and significantly increased atrophy rates in the inferior-lateral temporal gyrus, left posterior temporal lobe, and leftinferior frontal regions of SV-PPA patients. Brambati et al. [16] identified anterior cingulate, medial frontal, insular, and temporal atrophy in early-stage frontotemporal dementia.

In recent years, an increasing number of studies have demonstrated white matter abnormalities associated with FTLD. Pathological investigations have documented moderate 
frontal white matter gliosis with demyelination in frontotemporal dementia $[17,18]$ while MRI studies have shown white matter atrophy $[10,12,19]$ and reduced white matter integrity, using diffusion tensor imaging markers [20-23], in this population. Regions that myelinate later in brain development such as the frontal lobes and the temporal lobes are comprised of smaller axons and the myelin sheaths have fewer myelin lamellae [24]; therefore, these regions tend to be more vulnerable to breakdown by a variety of brain insults including neurodegenerative disorders such as FTLD and Alzheimer's disease [25-27]. Fiber-tracking analysis of diffusion tensor imaging data has also shown that the most prominent age-related deterioration of the white matter is observed in association fibers [28] that connect the regions last to complete myelination in the course of development [29].

There is limited longitudinal structural imaging data on FTLD, and the studies summarized above have primarily focused on gray matter atrophy [14-16, 30] with little attention to white matter changes. Tensor-based morphometry (TBM) is a relatively novel computational approach that can compare longitudinally acquired images and visualize the spatial profile of brain atrophy over time, including estimates of tissue volume loss at each voxel in the brain [31]. It was specifically chosen as the method of image analysis because it may be more sensitive in detecting changes in white matter volume as it does not require a segmentation step and thus avoids potential errors in accurate tissue classification due to partial volume effects. This approach has been successfully used to study neurodegenerative as well as normal brain aging [32-35]. We applied the TBM technique to assess and compare the longitudinal patterns of neuroanatomical changes over a 1-year period in a large cohort of patients with different clinical variants of FTLD. The main objectives of the current study were to (1) replicate previous findings of longitudinal regional brain atrophy in FTLD, (2) directly compare regional patterns of brain atrophy, particularly white matter change, between the clinical variants of FTLD, and (3) examine the relationship between brain atrophy and progression in clinical and behavioral symptoms.

\section{Material and Methods}

\section{Participants}

Patients with a diagnosis of FTLD between the ages of 46 and 78 were recruited from five academic medical centers. All subjects or their responsible family member received written and oral information about the study and signed written informed consents approved by the local institutional review board of the clinical sites prior to study participation. The inclusion and exclusion criteria have been previously reported [36]. Consensus criteria were used for diagnosing the syndromes of bvFTD, NF-PPA, and SV-PPA $[1,37]$. The number of subjects contributed by each center (anonymized) are detailed in table 1 and the distribution of patients with each clinical syndrome did not differ significantly across centers $\left(\chi^{2}=1.99\right.$, d.f. $=8, p=0.98$ ). Structural brain imaging was performed at baseline and approximately 1 year later.

\section{MRI Acquisition}

Baseline and follow-up MR images were acquired using a 1.5-tesla MR instrument with three-dimensional T1-weighted imaging sequences. The following scanning parameters were used: repetition time of $23 \mathrm{~ms}$, echo time of $5.66 \mathrm{~ms}$, flip angle of $25^{\circ}, 24 \mathrm{~cm}$ field of view, $256 \times 192$ acquisition matrix with slice thickness of $1.6 \mathrm{~mm}$, and acquired resolution of $0.9375 \times 0.9375 \times 1.6 \mathrm{~mm}$.

To ensure correct execution of specified image sequences, during the qualifying phase, image data from a volunteer were sent by all participating sites to the Mayo Clinic for checking of the pulse sequence parameters. Evaluation of signal-to-noise ratio and geometric distortion was accomplished by scanning a standardized phantom on a weekly basis to ensure that these parameters were within predetermined specifications. Each MR examination was logged into a database and checked for protocol compliance and image artifacts. 
Table 1. Number of subjects recruited by each center by clinical groups

\begin{tabular}{l|l}
\hline \multicolumn{2}{l}{ Dement Geriatr Cogn Disord 2013;35:34-50 } \\
\hline DOI: $\underline{10.1159 / 000345523}$ & $\begin{array}{l}\text { C) 2013 S. Karger AG, Basel } \\
\text { www.karger.com/dem }\end{array}$ \\
\hline
\end{tabular}

Lu et al.: Patterns of Brain Atrophy in Clinical Variants of FTLD

\begin{tabular}{lllll}
\hline & bvFTD & SV-PPA & NF-PPA & Total \\
\hline Center 1 & 8 & 4 & 4 & 16 \\
Center 2 & 6 & 3 & 4 & 13 \\
Center 3 & 4 & 2 & 4 & 10 \\
Center 4 & 7 & 4 & 5 & 16 \\
Center 5 & 2 & 3 & 2 & 7 \\
\hline
\end{tabular}

Overview of TBM

MRI data were analyzed with TBM, which allows investigation of regional volume changes in brain substructures by globally aligning serially acquired brain images into a common brain template before applying localized deformations to adjust each subject's anatomy to match the global group-averaged template. The methods were developed at the Laboratory of NeuroImaging and have been extensively tested and validated. Briefly, our implementation of TBM involves (1) nonlinearly deforming/warping the follow-up image to the baseline image using a mutual information-based inverse-consistent elastic registration algorithm (3DMI) and (2) using the three-dimensional Jacobian determinant maps of the deformation fields (mathematically defined by computing the determinant maps of the pointwise Jacobian operator applied to these deformations) to gauge the local volume differences between baseline and follow-up images. The determinant maps can be statistically analyzed on a voxel level to identify group differences in brain structure, such as localized atrophy or tissue excess.

Image Preprocessing

An automated Brain Surface Algorithm from Brainsuite [38] was applied, along with manual editing, to remove skull and other nonbrain tissues. We then corrected intensity inhomogeneity caused by nonuniformities in the radio frequency receiver coils using the N3 bias field algorithm proposed by Sled et al. [39]. All follow-up scans were first aligned to the same subject's baseline scan. To adjust for global differences in brain positioning, orientation, and scaling across individuals, both baseline and follow-up scans were subsequently registered using 6-, 7- and 9-parameter transformations (3 translations, 3 rotations, and 3 scales) to a single-target scan, randomly selected from our sample, that had been affinely registered to the stereotactic space defined by the International Consortium for Brain Mapping (ICBM-53) [40]. Globally aligned images were resampled in an isotropic space of 230 voxels along each axis ( $x, y$, and $\mathrm{z}$ dimensions) with an interpolated voxel size of $1 \mathrm{~mm}^{3}$.

To inspect the quality of the 9-parameter registrations, we used a three-dimensional visualization tool called REGISTER, which automatically overlays the arbitrary slice geometry of each scan pair in ICBM space. All scans were confirmed to have satisfactory alignment without noticeable distortion or mismatch.

Quantifying Structural Changes over Time

To quantify three-dimensional patterns of volumetric brain atrophy over time for each subject, an individual change map, or Jacobian map, was computed by nonlinearly registering the follow-up scan to the baseline scan using 3DMI [41].

For each subject, a local tissue growth/atrophy map was obtained by calculating the local Jacobian determinant (i.e., 'expansion factor') of the deformation field, which measures progressive volume contraction (Jacobian $<1$ ) or volume expansion (Jacobian $>1$ ), at each voxel. Jacobian maps were also spatially normalized across subjects by nonlinearly aligning all individual maps to a minimal deformation template (MDT), for regional comparisons and group statistical analysis. The MDT represented the average shape of $10 \mathrm{bvFTD}, 10 \mathrm{SV}-\mathrm{PPA}$, and $10 \mathrm{NF}$-PPA age- and gender-matched participants; the procedure to construct the MDT is detailed in Hua et al. [42]. Average Jacobian maps were computed by taking the mean at each voxel of the individual Jacobian maps across subjects. All results and statistical analyses are based on the Jacobian maps.

Regions of Interest

The regions of interest (ROI), comprised of frontal, temporal, parietal, and occipital lobes, as well as the ventromedial prefrontal cortex (VMPFC) and fusiform gyrus, were manually hand-traced by a trained 
Lu et al.: Patterns of Brain Atrophy in Clinical Variants of FTLD

anatomist on the MDT to generate binary masks for each lobe, which were subsequently used to summarize brain atrophy at a regional level in each group. Within each lobe, tissue types were distinguished by creating maps of gray and white matter, cerebrospinal fluid, and nonbrain tissues using the partial volume classification algorithm from the Brainsuite software program [38].

Cognitive, Behavioral, and Functional Assessment

A battery of cognitive, functional, and behavioral assessment was performed at baseline and at the follow-up visit. The specific instruments have been previously described in detail [37] and include the Clinical Dementia Rating (CDR) Scale [43], which contains two additional FTLD-specific items that assess alterations in behavior and language [37], the Neuropsychiatric Inventory (NPI) [44], and the Frontal Behavioral Inventory (FBI) [45]. For the above measures, higher scores indicate more severe symptomatology. Neuropsychological measures include the Mini-Mental State Examination (MMSE) [46], a short form of the California Verbal Learning Test (CVLT-IIS) [47], Digits Backward, Digit Symbol, and Similarities Subtests from the Wechsler Adult Intelligence Scales - Revised [48], Number Cancellation [49], Golden version of the Stroop Test [50], Simplified Trailmaking [37], Verbal Fluency [51], and Boston Naming Test (BNT) [52].

Two cognitive test composites were computed to present the neuropsychological scores in a concise manner. The rationale and details regarding the development of the composite scores were previously described [37]. The executive composite (EXEC) is comprised of six measures (Simplified Trailmaking, Digits Backward, Digit Symbol, Stroop Test, Number Cancellation, and number of errors summed across three difference tasks). A language composite (LANG) includes 5 variables (BNT, Letter Fluency, Semantic Fluency, Similarities Subtest, and total words recalled across the learning trials on the CVLT-IIS). A number of participants were unable to complete at least one of the tests at baseline or at follow-up; participants with missing data were excluded from these analyses.

\section{Statistical Analyses}

To illustrate systematic differences in atrophic rates between the three FTLD syndromes, we constructed voxel-wise statistical maps based on the Student's t statistic. The Jacobian maps of the bvFTD, SV-PPA, and NF-PPA groups were compared against each other using permutation-based twosample t tests to assess overall significance of group differences inside each ROI, corrected for multiple comparisons [53-56]. In brief, a null distribution for the group differences in atrophic rates (Jacobian values) at each voxel was constructed using 10,000 random permutations of the data. For each test, the subjects' diagnostic status (bvFTD vs. SV-PPA; bvFTD vs. NF-PPA; SV-PPA vs. NF-PPA) was randomly permutated and voxel-wise t tests were conducted to identify voxels more significant than $p=0.05$. The volume of voxels inside a defined ROI (i.e., frontal lobes) more significant than $p=0.05$ was computed for the real experiment and for the random assignments. A ratio, describing the fraction of the time the t-statistic was more extreme in the randomized tests than the original test, was calculated to yield an overall $\mathrm{p}$ value for the significance of the map (corrected for multiple comparison by permutation). A numeric summary of the mean atrophy rate (percent volume loss/gain over 1 year) for all voxels within each ROI was computed for each person. This approach has been used in prior work [32-35].

Behavioral and cognitive assessment results at baseline were compared between clinical groups using one-way analyses of covariance (ANCOVA) with age as covariate. Post hoc analyses of significant group differences were performed using pairwise $t$ tests. Changes in cognitive, behavioral, and functional performance over time were computed as simple difference scores between baseline and follow-up evaluations. FTLD-related subscales of NPI (Euphoria, Apathy, and Disinhibition) were dichotomized into presence or absence of symptoms and compared using $\chi^{2}$ tests. Linear regression analyses were performed to examine the association of baseline scores on behavioral scales with longitudinal brain changes (as represented by mean percent volume change) in the combined FTLD groups. CDR-Behavior, CDR-Language, and NPI subscales were dichotomized into presence or absence of symptoms then independent tests were performed to compare the percent volume change in VMPFC between symptom and no-symptom groups. The level of significance was set at $\alpha$ of 0.05 . 
Table 2. Demographic variables by FTLD clinical groups

\begin{tabular}{lccccc}
\hline Demographic variables & bvFTD $(\mathrm{n}=27)$ & SV-PPA $(\mathrm{n}=16)$ & NF-PPA $(\mathrm{n}=19)$ & F or $\chi^{2}$ & $\mathrm{p}$ \\
\hline Age, years & $60.4 \pm 9.0 *$ & $68.5 \pm 8.1^{*}$ & $64.6 \pm 6.6$ & 5.24 & 0.008 \\
Education, years & $15.6 \pm 2.2$ & $15.0 \pm 2.7$ & $14.3 \pm 2.5$ & 1.59 & 0.213 \\
Gender (males/females) & $17 / 10$ & $9 / 7$ & $8 / 11$ & 1.98 & 0.372 \\
White, \% & 89 & 100 & 95 & 1.84 & 0.179 \\
Time between scans, years & $1.07 \pm 0.12$ & $1.09 \pm 0.16$ & $1.12 \pm 0.20$ & 0.55 & 0.58 \\
\hline
\end{tabular}

$* \mathrm{p}<0.05$ : Post hoc Tukey test indicated that the bvFTD and SV-PPA groups differed significantly from each other but neither group differed significantly from the NF-PPA group. Results are presented as means \pm SD.

\section{Results}

\section{Baseline Characteristics}

The demographic characteristics and global cognitive ability are summarized in table 2. ANOVA analyses revealed a significant difference in age among the clinical groups. Post hoc Tukey tests revealed that the bvFTD group was significantly younger than the SV-PPA group. The age of the NF-PPA group was intermediate to and nonstatistically different from that of the other two groups.

Descriptive statistics for functional, behavioral, and cognitive assessments, separated by domains, are provided for each FTLD group in table 3. The pattern of deficits elucidated by these measures generally conforms to the impairments characteristic of each syndrome. The bvFTD subjects exhibited significantly worse scores than either SV-PPA or NF-PPA groups on measures of behavioral and personality alterations including the CDR-Behavior subscale, the FBI, and the NPI; the two language groups did not differ significantly from each other on these instruments. In addition, significantly greater number of bvFTD patients exhibited symptoms of euphoria, apathy, and disinhibition on the NPI than the two language groups. On neuropsychological testing, no significant group differences were observed on the EXEC score although the NF-PPA group performed significantly worse than the bvFTD and the SV-PPA groups on the Digit Backward subtest $(p=0.017)$. There were no significant group differences on the other measures that comprise the EXEC domain score ( $p>0.07)$.

With regards to language functioning, a significant group difference was observed on the LANG composite with the SV-PPA group scoring significantly lower than the bvFTD and NP-PPA groups. Post hoc analysis of individual measures indicated that the SV-PPA group performed significantly worse than bvFTD and NF-PPA groups on measures of semantic knowledge and retrieval, semantic verbal fluency, and verbal abstraction (BNT, Category Fluency, and Similarities), but no significant group difference was observed for phonemic verbal fluency. The bvFTD and NF-PPA groups did not differ on any of the language measures. On the CDR-Language subscale, both SV-PPA and NF-PPA groups displayed significantly greater impairment than the bvFTD group; the two PPA groups did not differ from each other on this measure.

\section{Brain Atrophy Rates}

Individual Jacobian maps showing the relative change in volume from baseline to followup were averaged within the bvFTD, SV-PPA, and NF-PPA groups to visualize the regional rates of change for each clinical syndrome (fig. 1). These maps show the mean percent tissue 
Table 3. Baseline scores for cognitive, behavioral, and functional assessment across the three FTLD syndromes, adjusted for age

\begin{tabular}{|c|c|c|c|c|c|c|c|c|}
\hline & \multicolumn{2}{|c|}{ bvFTD } & \multicolumn{2}{|c|}{ SV-PPA } & \multicolumn{2}{|c|}{ NF-PPA } & \multirow[t]{2}{*}{$\mathrm{F}$} & \multirow[t]{2}{*}{$\mathrm{p}$} \\
\hline & $\mathrm{n}$ & mean \pm SD & $\mathrm{n}$ & mean $\pm \mathrm{SD}$ & $\mathrm{n}$ & mean $\pm \mathrm{SD}$ & & \\
\hline \multicolumn{9}{|l|}{ Behavioral measures } \\
\hline CDR Sum of Boxes & 27 & $4.3 \pm 2.3^{\mathrm{a}}$ & 16 & $3.0 \pm 3.2$ & 19 & $2.1 \pm 2.3^{b}$ & 3.73 & 0.030 \\
\hline CDR-Behavior & 27 & $1.40 \pm 0.75^{\mathrm{a}}$ & 16 & $0.65 \pm 0.54^{\mathrm{b}}$ & 19 & $0.36 \pm 0.58^{\mathrm{b}}$ & 14.87 & $<0.0001$ \\
\hline CDR-Language & 27 & $0.42 \pm 0.54^{\mathrm{a}}$ & 16 & $1.53 \pm 0.61^{\mathrm{b}}$ & 19 & $1.69 \pm 0.80^{\mathrm{b}}$ & 23.11 & $<0.0001$ \\
\hline FBI score & 25 & $27.4 \pm 12.6^{\mathrm{a}}$ & 16 & $17.2 \pm 11.2^{\mathrm{b}}$ & 19 & $13.7 \pm 9.2^{\mathrm{b}}$ & 8.13 & 0.0008 \\
\hline NPI total score & 26 & $30.9 \pm 18.8^{\mathrm{a}}$ & 16 & $16.2 \pm 16.7^{\mathrm{b}}$ & 19 & $11.9 \pm 12.9^{\mathrm{b}}$ & 7.39 & 0.001 \\
\hline Euphoria, yes/no & 26 & $11 / 15$ & 16 & $2 / 14$ & 19 & $2 / 17$ & 14.90 & 0.0006 \\
\hline Apathy, yes/no & 26 & $22 / 4$ & 16 & $10 / 6$ & 19 & $4 / 15$ & 18.45 & $<0.0001$ \\
\hline Disinhibition, yes/no & 26 & $18 / 8$ & 16 & $7 / 9$ & 19 & $3 / 16$ & 12.67 & 0.002 \\
\hline \multicolumn{9}{|l|}{ Cognitive domain/tests } \\
\hline \multicolumn{9}{|l|}{ Global cognitive ability } \\
\hline MMSE & 21 & $26.1 \pm 3.1$ & 14 & $23.6 \pm 4.4$ & 10 & $23.7 \pm 6.2$ & 1.54 & 0.226 \\
\hline Executive composite (EXEC) & 21 & $0.147 \pm 0.68$ & 15 & $-0.015 \pm 0.55$ & 10 & $-0.286 \pm 0.93$ & 1.34 & 0.272 \\
\hline Trailmaking Time, s & 21 & $52.3 \pm 30.8$ & 15 & $60.9 \pm 37.7$ & 10 & $67.4 \pm 38.9$ & 0.66 & 0.524 \\
\hline Digits Backward & 21 & $4.1 \pm 1.3^{\mathrm{a}}$ & 15 & $4.0 \pm 1.3^{\mathrm{a}}$ & 10 & $2.7 \pm 1.3^{\mathrm{b}}$ & 4.47 & 0.017 \\
\hline Digit Symbol & 21 & $48.8 \pm 15.1$ & 15 & $48.3 \pm 18.2$ & 10 & $46.6 \pm 18.4$ & 0.06 & 0.939 \\
\hline Number Cancellation & 21 & $28.5 \pm 10.6$ & 15 & $28.9 \pm 8.1$ & 10 & $26.9 \pm 10.1$ & 0.16 & 0.853 \\
\hline Stroop Interference & 21 & $29.8 \pm 19.3$ & 15 & $17.7 \pm 11.2$ & 10 & $19.5 \pm 11.5$ & 2.71 & 0.078 \\
\hline Language composite (LANG) & 21 & $0.33 \pm 0.55^{\mathrm{a}}$ & 15 & $-0.64 \pm 0.73^{b}$ & 10 & $0.26 \pm 0.87^{\mathrm{a}}$ & 8.20 & 0.001 \\
\hline BNT & 21 & $23.1 \pm 7.2^{\mathrm{a}}$ & 15 & $5.0 \pm 5.2^{\mathrm{b}}$ & 10 & $23.5 \pm 8.6^{\mathrm{a}}$ & 29.74 & $<0.0001$ \\
\hline Letter Fluency & 21 & $25.3 \pm 13.3$ & 15 & $20.2 \pm 13.1$ & 10 & $16.5 \pm 10.9$ & 1.64 & 0.206 \\
\hline Category Fluency & 21 & $28.1 \pm 9.4^{\mathrm{a}}$ & 15 & $13.2 \pm 11.5^{\mathrm{b}}$ & 10 & $27.3 \pm 13.1^{\mathrm{a}}$ & 7.65 & 0.002 \\
\hline Verbal Similarities & 21 & $15.3 \pm 6.4^{\mathrm{a}}$ & 15 & $9.1 \pm 7.3^{\mathrm{b}}$ & 10 & $18.4 \pm 8.0^{\mathrm{a}}$ & 5.41 & 0.008 \\
\hline CVLT-IIS Learning & 21 & $20.3 \pm 5.1^{\mathrm{a}}$ & 15 & $13.5 \pm 7.3^{\mathrm{b}}$ & 10 & $19.7 \pm 11.1$ & 3.46 & 0.041 \\
\hline
\end{tabular}

Groups denoted by different superscript letters differ by $\mathrm{p}<0.05$ after pair-wise t test.

loss (in blue color) or ventricular enlargement (in red color) over the 1-year interval. In the bvFTD group (top row), the maps show progressive atrophy in the superior and middle frontal lobes as well as the anterior temporal lobes with relative sparing of the posterior regions. They also demonstrate expansion of the lateral ventricles, especially in the anterior regions. In the SV-PPA group (middle row), the most atrophy was observed in the anterior, middle, and inferior temporal lobes, as well as expansion of the anterior and posterior lateral ventricles, with relative sparing of the frontal regions. For the NF-PPA group (bottom row), the maps suggest more widespread progressive atrophy throughout the frontal, temporal, and parietal regions. To test whether there were statistically significant regional differences in volume change between groups over this 1-year period, we conducted regional voxel-wise tests controlled for multiple comparisons.

\section{bvFTD versus SV-PPA}

Jacobian maps of the bvFTD group were compared directly against the SV-PPA group to yield the statistical maps shown in figure 2 , which display regions of significant difference in atrophy rates between groups. Permutation tests provided regional $\mathrm{p}$ values corrected for multiple comparisons. Compared to SV-PPA, the bvFTD group demonstrated significantly higher rate of atrophy in the frontal lobes (top row; $p=0.005$ ), particularly in the frontal white matter $(p=0.002)$ involving the superior, middle, and inferior frontal regions (greater 
Dementia

and Geriatric

Cognitive Disorders
Dement Geriatr Cogn Disord 2013;35:34-50

DOI: $10.1159 / 000345523$

Lu et al.: Patterns of Brain Atrophy in Clinical Variants of FTLD

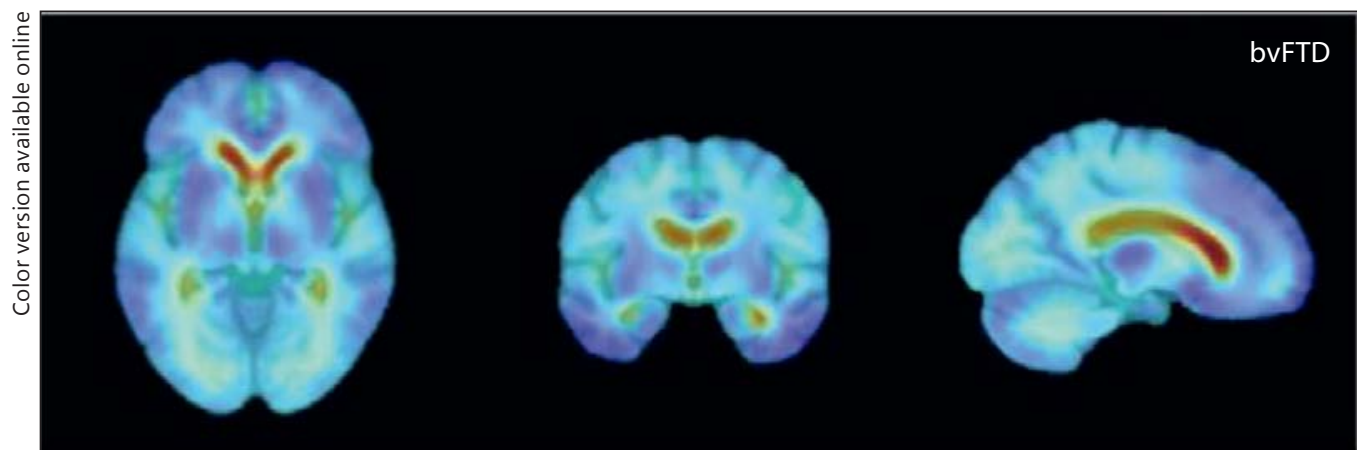

$+20 \%$
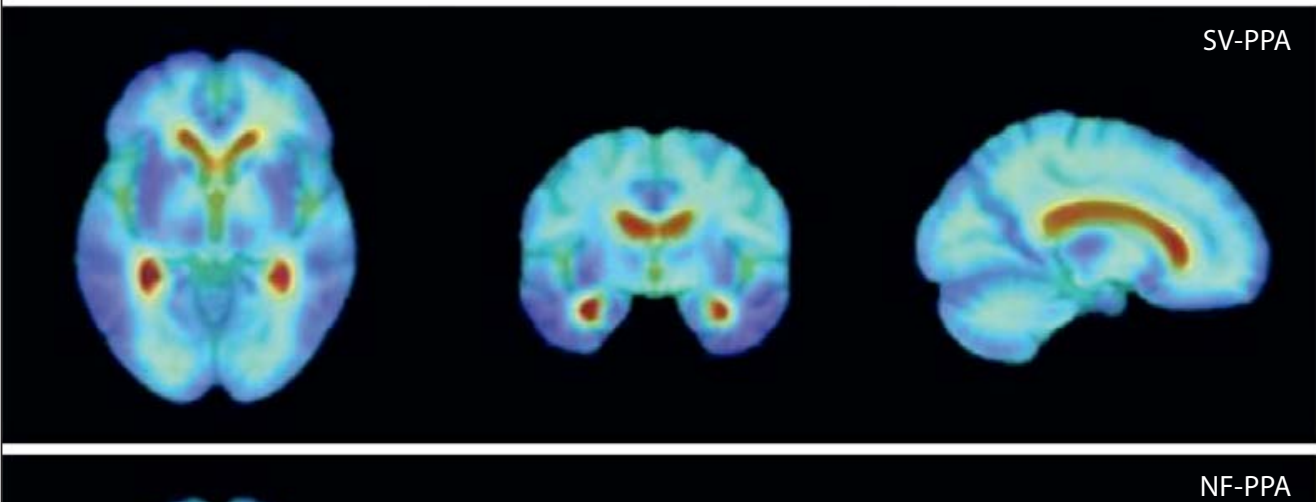

NF-PPA

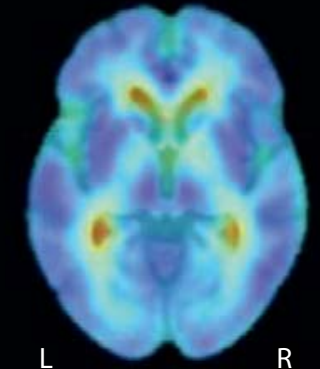

R
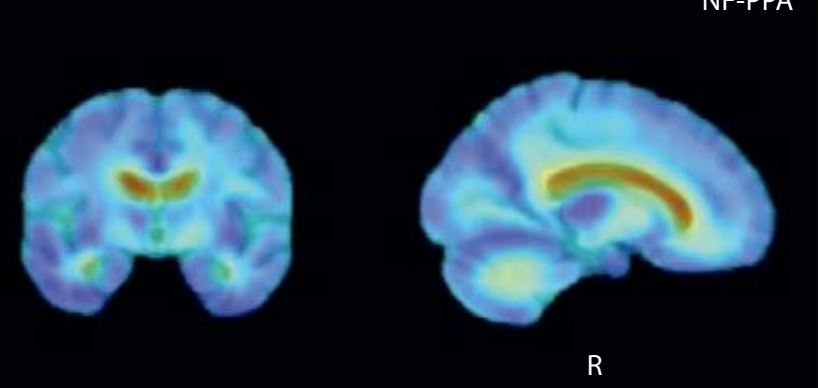

$-10 \%$

Fig. 1. Regional brain atrophy over 1 year for bvFTD, SV-PPA, and NF-PPA syndromes of FTLD. Jacobian maps showing the mean annual rate of atrophy of brain tissue (in blue color) and ventricular enlargement (in red color) for the bvFTD (top row), SV-PPA (middle row), and NF-PPA (bottom row) subjects. These tissue changes are shown as percentages, relative to the baseline scan, and are computed within each individual before averaging across subjects in the group.

on the right side). Conversely, SV-PPA demonstrated significantly higher atrophy rates than bvFTD in the left inferior temporal gyrus involving the fusiform gyrus (bottom row, left, $\mathrm{p}=$ 0.007), but not on the right. The SV-PPA group also exhibited significantly greater expansion in the posterior ventricles when compared to the bvFTD group $(\mathrm{p}=0.015)$.

\section{NF-PPA versus bvFTD}

When bvFTD was compared to NF-PPA (fig. 3), the NF-PPA group exhibited significantly higher rates of progressive atrophy in the parietal lobes $(p=0.022)$ and posterior frontal white matter $(p=0.049)$ compared to the bvFTD group (top row). Higher rates of atrophy were also seen in the inferior temporal region though permutation tests were only marginally significant $(\mathrm{p}=0.07)$. Conversely, the bvFTD group demonstrated significantly greater atrophy in the ventromedial prefrontal region $(p=0.017)$ compared to the NF-PPA group. 

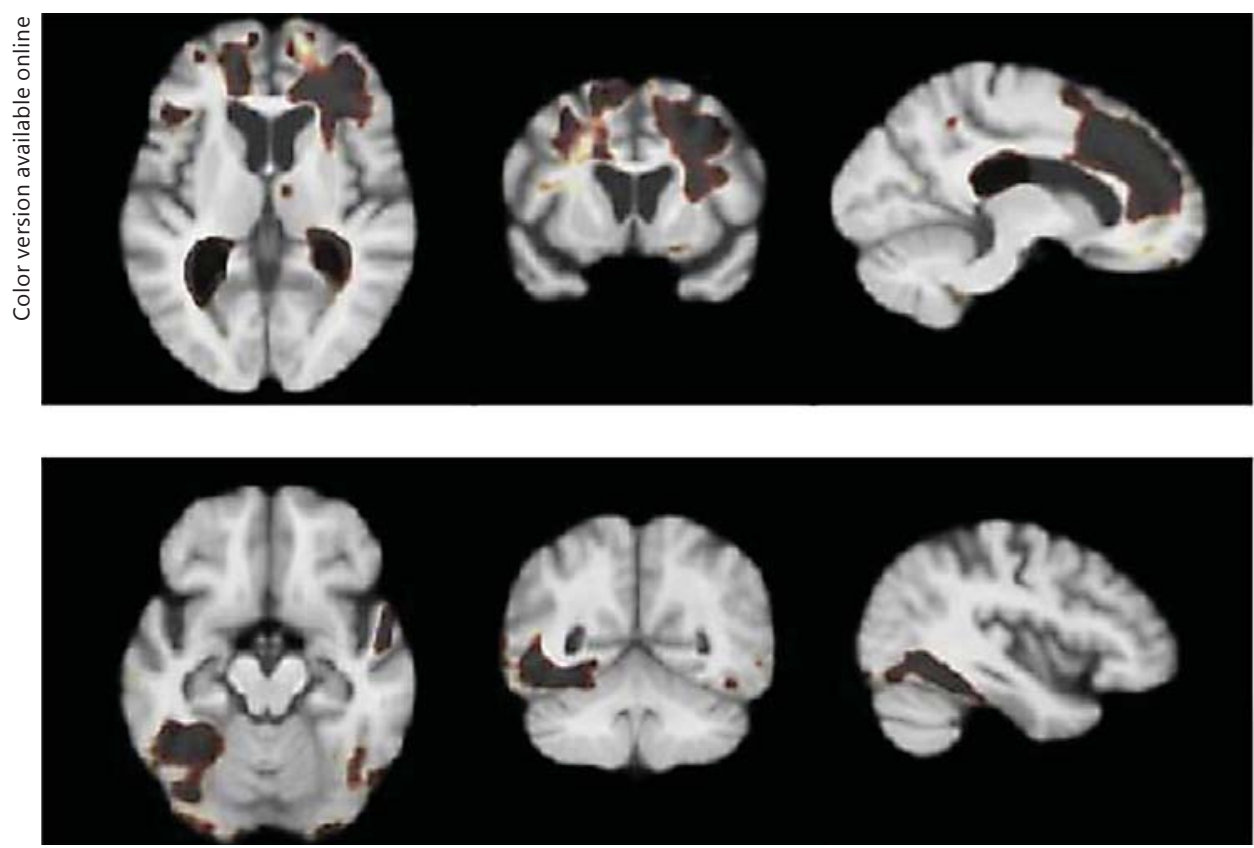

Fig. 2. Statistical maps showing regions of significant differences in atrophy rates over 1 year between bvFTD and SV-PPA groups. The top row depicts significance maps showing that the bvFTD demonstrate significantly greater annual atrophy rate (as indicated in brown color) in the right frontal white matter than the SV-PPA group. Significantly greater expansion in the posterior lateral ventricles of the SV-PPA group, relative to the bvFTD group, is also shown. In the bottom row, significance maps show regions of greater atrophy in the left fusiform gyrus of the SV-PPA group compared to the bvFTD group.
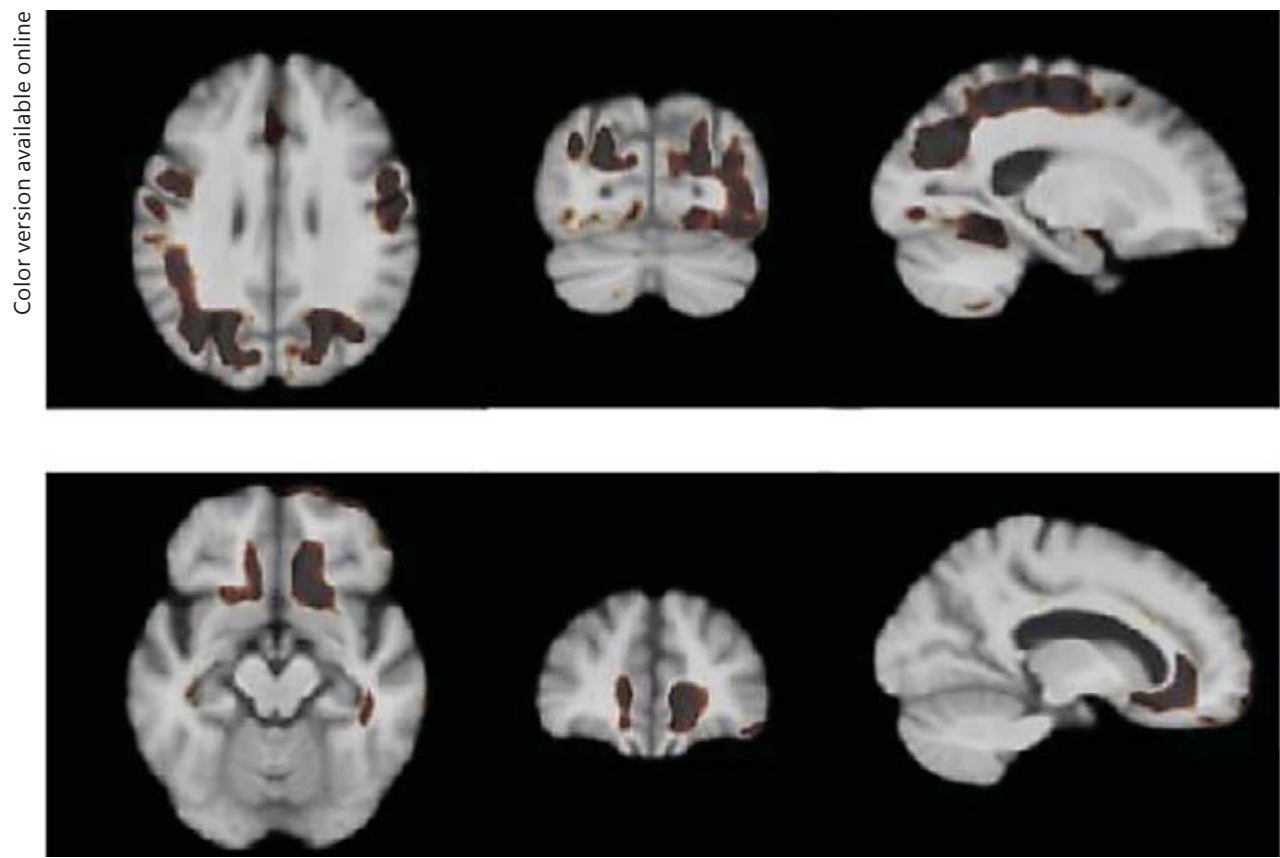

Fig. 3. Statistical maps showing regions of significant differences in atrophy rates over 1 year between bvFTD and NF-PPA groups. Significance maps showing that the NF-PPA group demonstrate significantly greater annual atrophy rate (as indicated in brown color) in the superior parietal white matter compared to the bvFTD (top row). bvFTD had significantly greater rate of atrophy in the ventromedial prefrontal region compared to the NF-PPA group (bottom row). 

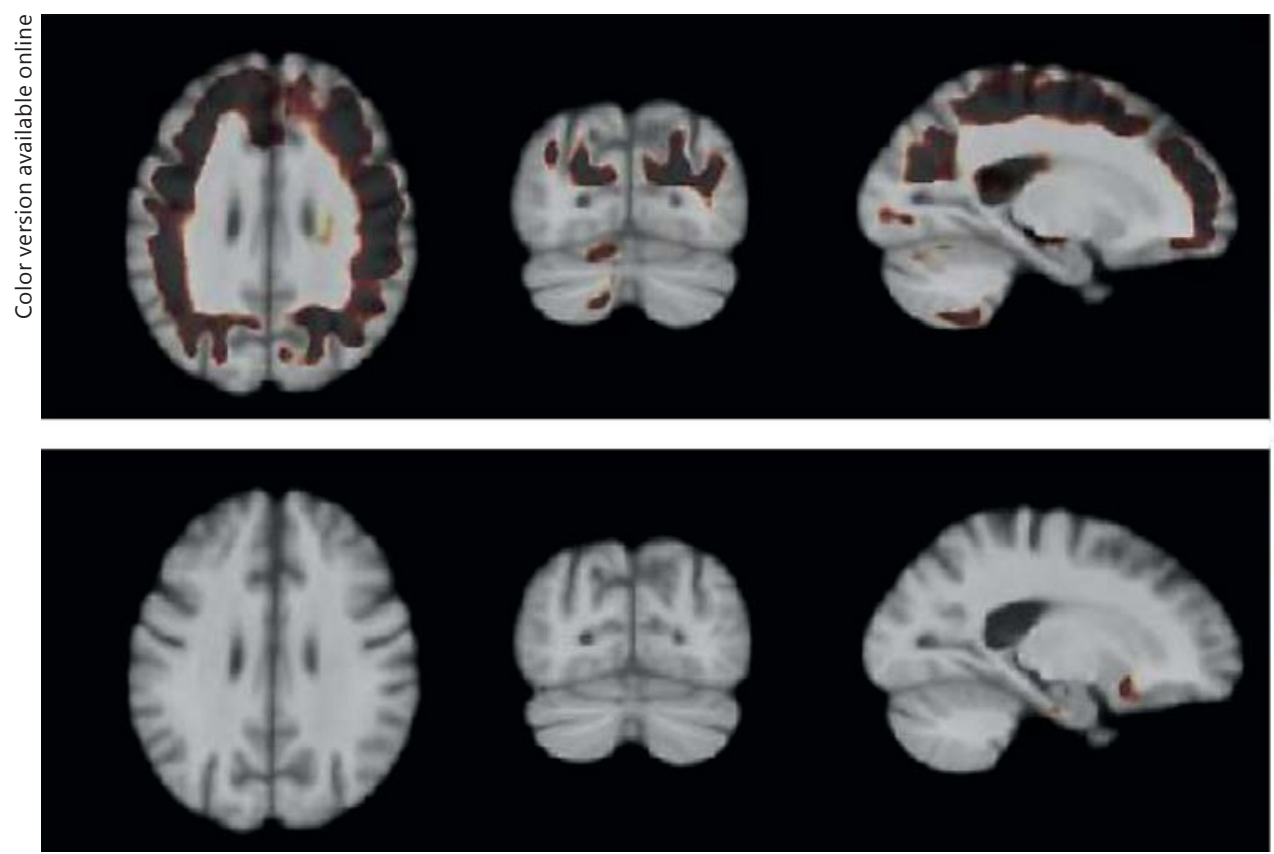

$\mathrm{p}<0.05$

Fig. 4. Statistical maps showing regions of significant differences in atrophy rates over 1 year between SV-PPA and NF-PPA groups. Significance maps showing that the NF-PPA group demonstrate significantly greater diffuse atrophy, including the frontal, parietal, and occipital lobes compared to the SV-PPA subjects (top row). In contrast, the SV-PPA group did not show any regions of greater atrophy relative to the NF-PPA group (bottom row).

\section{NF-PPA versus SV-PPA}

NF-PPA demonstrated significantly higher atrophy rates in the frontal lobes $(p=0.001)$, temporal lobes $(p=0.047)$, and parietal lobes $(p=0.002)$ compared to SV-PPA (fig. 4). In contrast, SV-PPA showed no regions of significantly greater atrophy than NF-PPA.

\section{Change in Performance on Cognitive, Behavioral, and Functional Measures}

At 1-year follow-up, all groups demonstrated increased behavioral symptomatology on measures of behavioral and functional abilities (table 4); however, ANCOVA adjusted for age at baseline did not reveal any significant differences in the change scores among the three clinical variants $(p>0.22)$. On neuropsychological measures, the change scores did not differ significantly among the three FTLD groups on either EXEC or LANG composite measures or any of the individual measures ( $p>0.09)$. Numerically, the bvFTD group demonstrated greater decline in performance across the neurocognitive measures, but the group comparisons were not statistically significant.

Pearson correlation, partialling out diagnosis and age, revealed a marginally significant relationship between rate of change in total white matter volume and change in EXEC score $(r=0.300, p=0.049)$. No other longitudinal cognitive-structural associations reached statistical significance $(\mathrm{p}>0.12)$.

\section{Relationship between Baseline Behavior and Longitudinal Brain Atrophy}

Mean annualized Jacobian values within each ROI, indicating rates of atrophy (in percent volume change per year), were computed for each subject. Simple linear regressions were performed to examine the impact of FTLD-specific behavioral symptoms at 
Table 4. Change scores at follow-up for cognitive, behavioral, and functional assessment across the three FTLD syndromes - adjusted for age

\begin{tabular}{|c|c|c|c|c|c|c|c|c|}
\hline & \multicolumn{2}{|c|}{ bvFTD } & \multicolumn{2}{|c|}{ SV-PPA } & \multicolumn{2}{|c|}{ NF-PPA } & \multirow[t]{2}{*}{$\mathrm{F}$} & \multirow[t]{2}{*}{$\mathrm{p}$} \\
\hline & $\mathrm{n}$ & mean \pm SD & $\mathrm{n}$ & mean $\pm \mathrm{SD}$ & $\mathrm{n}$ & mean \pm SD & & \\
\hline \multicolumn{9}{|l|}{ Behavioral measures } \\
\hline CDR Sum of Boxes & 24 & $2.55 \pm 2.7$ & 16 & $2.88 \pm 2.0$ & 16 & $2.30 \pm 3.4$ & 0.17 & 0.842 \\
\hline CDR-Behavior & 24 & $0.23 \pm 0.59$ & 16 & $0.59 \pm 0.64$ & 16 & $0.28 \pm 0.60$ & 1.54 & 0.225 \\
\hline CDR-Language & 24 & $0.13 \pm 0.63$ & 16 & $0.09 \pm 0.58$ & 16 & $0.41 \pm 0.99$ & 0.90 & 0.414 \\
\hline FBI score & 22 & $5.99 \pm 8.26$ & 14 & $7.69 \pm 9.56$ & 18 & $4.42 \pm 8.25$ & 0.55 & 0.580 \\
\hline NPI total score & 27 & $3.11 \pm 19.4$ & 16 & $10.22 \pm 16.7$ & 19 & $2.38 \pm 12.9$ & 1.30 & 0.280 \\
\hline \multicolumn{9}{|l|}{ Cognitive domain/tests } \\
\hline \multicolumn{9}{|l|}{ Global cognitive ability } \\
\hline MMSE & 21 & $-2.40 \pm 4.0^{\mathrm{a}}$ & 13 & $-8.08 \pm 5.1^{b}$ & 10 & $-4.00 \pm 4.6$ & 5.22 & 0.010 \\
\hline Executive composite (EXEC) & 21 & $-0.44 \pm 0.40$ & 15 & $-0.26 \pm 0.52$ & 10 & $-0.16 \pm 0.25$ & 1.68 & 0.199 \\
\hline Trailmaking Time, s & 21 & $16.1 \pm 31.8$ & 15 & $5.5 \pm 46.4$ & 10 & $7.5 \pm 19.5$ & 0.39 & 0.677 \\
\hline Digits Backward & 21 & $-0.76 \pm 1.18$ & 15 & $-0.54 \pm 1.41$ & 10 & $0.00 \pm .82$ & 1.31 & 0.280 \\
\hline Digit Symbol & 21 & $-6.78 \pm 10.4$ & 15 & $-4.10 \pm 17.1$ & 10 & $-4.82 \pm 9.4$ & 0.18 & 0.837 \\
\hline Number Cancellation & 21 & $-2.5 \pm 5.7$ & 15 & $-4.8 \pm 8.8$ & 10 & $-3.2 \pm 3.8$ & 0.45 & 0.642 \\
\hline Stroop Interference & 21 & $-7.4 \pm 10.7$ & 15 & $-4.9 \pm 8.3$ & 10 & $-4.0 \pm 8.0$ & 0.50 & 0.608 \\
\hline Language composite (LANG) & 21 & $-0.35 \pm 0.25$ & 15 & $-0.35 \pm 0.23$ & 10 & $-0.25 \pm 0.25$ & 0.60 & 0.555 \\
\hline BNT & 21 & $-2.11 \pm 3.84$ & 15 & $-1.78 \pm 2.83$ & 10 & $-1.89 \pm 1.73$ & 0.04 & 0.957 \\
\hline Letter Fluency & 21 & $-5.15 \pm 6.99$ & 15 & $-6.12 \pm 6.05$ & 10 & $-0.41 \pm 6.15$ & 2.48 & 0.096 \\
\hline Category Fluency & 21 & $-6.52 \pm 4.54$ & 15 & $-4.80 \pm 4.56$ & 10 & $-5.41 \pm 6.08$ & 0.48 & 0.623 \\
\hline Verbal Similarities & 21 & $-2.26 \pm 3.84$ & 15 & $-3.51 \pm 3.35$ & 10 & $-3.30 \pm 7.06$ & 0.32 & 0.727 \\
\hline CVLT-IIS Learning & 21 & $-2.79 \pm 4.98$ & 15 & $-2.10 \pm 2.96$ & 10 & $-1.59 \pm 4.03$ & 0.28 & 0.757 \\
\hline
\end{tabular}

Groups denoted by different superscript letters differ by $\mathrm{p}<0.05$ after pair-wise t test.

Table 5. Percent volume change in VMPFC over 1 year in those with and without behavioral symptoms

\begin{tabular}{|c|c|c|c|c|c|c|}
\hline \multirow[t]{2}{*}{ Behavioral measures } & \multicolumn{2}{|c|}{ With symptoms } & \multicolumn{2}{|c|}{ Without symptoms } & \multirow[t]{2}{*}{$\mathrm{t}$} & \multirow[t]{2}{*}{$\mathrm{p}$} \\
\hline & $\mathrm{n}$ & mean \pm SD & $\mathrm{n}$ & mean \pm SD & & \\
\hline CDR-Behavior & 42 & $-3.23 \pm 2.30$ & 20 & $-1.45 \pm 2.27$ & 2.86 & 0.006 \\
\hline CDR-Language & 47 & $-2.56 \pm 2.29$ & 15 & $-2.93 \pm 2.88$ & 0.51 & 0.611 \\
\hline NPI-Euphoria & 42 & $-3.88 \pm 2.07$ & 19 & $-2.25 \pm 2.21$ & 2.72 & 0.009 \\
\hline NPI-Apathy & 36 & $-3.41 \pm 2.02$ & 25 & $-1.82 \pm 2.35$ & 2.82 & 0.007 \\
\hline NPI-Disinhibition & 28 & $-3.48 \pm 1.96$ & 33 & $-2.15 \pm 2.39$ & 2.35 & 0.022 \\
\hline
\end{tabular}

baseline on rates of brain atrophy for the combined FTLD groups. Percent volume change in VMPFC was significantly associated with several measures of behavioral symptomatology including CDR-Behavior $(\beta=-1.78, \mathrm{SE}=0.62, \mathrm{p}=0.006)$, NPI subscales Euphoria $(\beta=-1.63, \mathrm{SE}=0.60, \mathrm{p}=0.009)$, Apathy $(\beta=-1.59, \mathrm{SE}=0.56, \mathrm{p}=0.007)$, and Disinhibition $(\beta=-1.33, \mathrm{SE}=0.566, \mathrm{p}=0.022)$. Percent volume change in VMPFC was then compared between subjects with and without symptoms on FTLD-specific CDR and NPI subscales. The results are summarized in table 5, indicating significantly greater VMPFC volume loss over 1 year for those with behavioral symptoms at baseline.

In addition, the NPI-Euphoria subscale had significant associations with percent volume loss in total white matter $(\beta=1.37, \mathrm{SE}=0.60, \mathrm{p}=0.025)$, frontal lobes $(\beta=-1.39, \mathrm{SE}=0.56$, 
$\mathrm{p}=0.017)$, and temporal lobes $(\beta=-1.15, \mathrm{SE}=0.56, \mathrm{p}=0.045)$. Frontal Behavioral Inventory score was significantly associated with percent volume loss in total white matter $(\beta=$ $-0.056, \mathrm{SE}=0.022, \mathrm{p}=0.013)$ and frontal lobes $(\beta=-0.047, \mathrm{SE}=0.021, \mathrm{p}=0.030)$ while the association with frontal white matter was marginally significant $(\beta=0.001, \mathrm{SE}=0.0006$, $\mathrm{p}=0.062$ ). CDR-Language did not have any significant associations with atrophy rate in the brain regions assessed $(p>0.39)$.

\section{Discussion}

Using TBM, we mapped and compared regional differences in the progression of brain atrophy over a 1-year period among patients with three clinical syndromes of FTLD. In comparison to the language variants, bvFTD subjects demonstrated significantly higher rates of frontal atrophy, though there was variability in the specific regions of difference. The bvFTD group exhibited greater atrophy than the NF-PPA group in the VMPFC, but showed greater atrophy in the inferior, middle and superior frontal gyri compared to SV-PPA. The SV-PPA group showed higher annual atrophy rates than bvFTD in the left inferior temporal lobes, including the fusiform gyrus, which corresponds to the language disturbances and prosopagnosia that are specific to SV-PPA. Greater expansion of the posterior horns of the lateral ventricles was also observed in SV-PPA compared to bvFTD. The patterns of regional atrophy reported in our SV-PPA group are very consistent with the literature, particularly the involvement of the fusiform gyrus $[13,16]$. Other longitudinal imaging studies using TBM or similar approaches also described gray matter contraction in the temporal pole and increased rates of volume loss in the right inferolateral temporal gyrus of SV-PPA subjects compared to healthy controls, with sparing of parietal, occipital, and dorsal frontal brain regions $[15,16]$.

While the above results replicate previous reports on the distribution of brain atrophy in clinical subtypes of FTLD, a novel finding of our study is that the bvFTD subjects demonstrated significantly more longitudinal white matter contraction than the SV-PPA group in the superior and inferior frontal lobes. Even though select cross-sectional studies have shown white matter atrophy in FTLD on structural MRI $[10,12,19]$, the data on longitudinal white matter changes in FTLD is much more limited. White matter damage, specifically moderate frontal white matter gliosis with demyelination, has been documented pathologically in frontotemporal dementia patients [17, 18]. Broe et al. [57] have suggested that white matter atrophy occurs in later stages of frontotemporal dementia and reflects severe gray matter and neuronal cell loss, but other reports have demonstrated that white matter atrophy occurs during earlier stages of the disease [19]. Furthermore, recent studies have reported change in white matter integrity of patients with frontotemporal dementia using diffusion tensor imaging markers [20-23]. Our findings support and extend existing literature suggesting that white matter degeneration may be a direct consequence and a major pathological feature of bvFTD, consistent with histopathological evidence of tau deposition in white matter of bvFTD patients [58].

Myelination and the maintenance and repair of these highly vulnerable tissues is responsible for the exquisitely synchronized timing of action potentials that underlie neuronal network oscillations necessary for optimal human cognitive and behavioral functioning [59, 60]. Regions such as the frontal and temporal lobes that myelinate later in the developmental process have fewer oligodendrocytes supporting greater numbers of axons compared to earlier-myelinated regions (e.g., primary sensorimotor regions), and the axons are smaller with fewer myelin lamellae [24]. Oligodendrocytes in these cortical association areas have particularly high metabolic demands in order to maintain the widely distributed network 
of axons, which makes these axons more susceptible to breakdown from pathological processes [59]. The symptoms most often manifested by patients with FTLD (behavioral inhibition, language disturbance) may result from disruption of the circuitry containing late-myelinating, high-workload fibers and eventual white matter degradation in the cortical association regions [60].

Another novel finding in our study is that the pattern of atrophy exhibited by our NF-PPA group was more global than expected, involving frontal, temporal, and parietal regions, and they did not demonstrate the characteristic left-dominant pattern associated with this population $[61,62]$. Even though the bvFTD group exhibited greater atrophy in the VMPFC than NF-PPA participants, the NF-PPA group displayed a significantly greater rate of atrophy than either bvFTD or SV-PPA groups in the posterior frontal and parietal lobes, particularly in the white matter, further highlighting the involvement of white matter in the pathology of FTLD. As the disease progresses, atrophy in NF-PPA can extend posteriorly along the Sylvian fissure into the parietal lobe [62]. However, we also acknowledge the possibility that the observed increase in parietal atrophy may indicate underlying Alzheimer's pathology in some of the NF-PPA subjects. Several reports have documented cases of autopsy-confirmed Alzheimer's pathology in patients who presented with clinical symptoms of NF-PPA [63-69]. Alternatively, a subset of patients with nonfluent aphasia has been documented to progress into corticobasal degeneration, which share a common pathology of tau inclusion and exhibit frontoparietal lobe atrophy on neuroimaging [70]. Therefore, our NF-PPA group may represent an admixture of heterogeneous etiology, which can only be verified through pathological studies.

Our results revealed that specific behavioral symptoms at baseline predicted longitudinal changes in corresponding brain regions. The presence of frontal lobe-mediated behavioral manifestations, such as euphoria, apathy, and disinhibition, was associated with greater longitudinal volume loss of the VMPFC. Measures that assess a broader spectrum of both 'positive' and 'negative' frontal-executive symptoms were sensitive to rates of atrophy in frontal lobes and white matter volume. Similar structural-function relationships were observed within SV-PPA and NF-PPA subgroups when examined separately (data not shown). These findings underscore the specificity in the relationship between focal anatomical abnormalities and behavioral expression in this population, which traverses the boundaries of putative clinical definitions. Examination of the relationship between prospective changes in brain volume with deterioration in clinical and cognitive symptoms yielded only a marginally significant correlation between change in EXEC score and total white matter volume but not with more specific regions. The absence of more striking associations may be partially attributed to floor effects as performance on select measures may already be severely impaired at baseline for specific syndromic groups (i.e., BNT for SV-PPA), which then obscures the magnitude of the change scores.

The strengths of the present study include the longitudinal design in which each subject acts as his/her own control; measurement of intraindividual rates of change yields greater sensitivity for detection of subtle brain changes over time and overcomes the problem of interindividual variation in brain structure. Several important study limitations should also be acknowledged. Combining scans from multiple centers increases the power of the study but introduces the possibility of intercenter variability in diagnosis, MR instrument, and procedures. However, the participating centers are known for their expertise in FTLD, and the study design is balanced such that each site contributed participants from each clinical group, thus scanner differences affect all subjects and is not specific to one clinical subgroup. Another limitation is the uncertainty of the definitive diagnosis or the underlying histopathology of the patients studied. Careful follow-up of patients without a change in their clinical diagnoses may improve the gold standard in clinical studies. The SV-PPA group was 
significantly older than the bvFTD group, but adjusting for age did not meaningfully alter the results. Furthermore, one would expect increased age to be associated with greater rates of atrophy, but the younger bvFTD group actually exhibited more atrophy than SV-PPA.

The ability to track regional atrophy over time can help refine differential diagnosis and monitor disease progression in FTLD and identify patterns of neurodegeneration specific to each clinical syndrome. Even though the subjects were scanned only 1 year apart, our TBM data were able to show distinct regional patterns of atrophy, suggesting that this method can be a sensitive approach for detecting syndrome-specific longitudinal brain changes. Additionally, significantly greater progression of white matter loss was observed in the bvFTD group compared to the semantic-variant syndromes of FTLD, which was also related to frontal lobe behavioral symptoms. Even though there are limitations to our study as the findings in the NF-PPA group were less specific, further investigation of early changes in white matter would be merited given that it may provide potentially sensitive indicators for detecting syndrome-specific longitudinal brain changes.

\section{Acknowledgments}

This work was supported by grants K23-AG028727 and R01-AG034499 from the National Institute of Health/National Institute of Aging (NIH/NIA) and a grant from the Alzheimer's Association (NIRG-0760424). Further support for this study came from NIH grants P50 AG-16570 (UCLA Alzheimer's Disease Research Center), R01-AG023195, R01-AG11378, P50 AG-16574 (Mayo Alzheimer's Disease Research Center), P30-AG19610 (Arizona Alzheimer Disease Center), R01-AG022983, P50-AG023501 (UCSF Alzheimer Disease Research Center) U01 AG016976 (National Alzheimer's Coordinating Center), and the California Alzheimer's Disease Center. Algorithm development for this study was also funded by the NIA, NIBIB, the National Library of Medicine, and the National Center for Research Resources (AG016570, EB01651, LM05639, RR019771 to PT).

\section{References}

1 Neary D, Snowden JS, Gustafson L, Passant U, Stuss D, Black S, Freedman M, Kertesz A, Robert PH, Albert M, Boone K, Miller BL, Cummings J, Benson DF: Frontotemporal lobar degeneration: a consensus on clinical diagnostic criteria. Neurology 1998;51: 1546-1554.

2 Gorno-Tempini ML, Hillis AE, Weintraub S, Kertesz A, Mendez M, Cappa SF, Ogar JM, Rohrer JD, Black S, Boeve BF, Manes F, Dronkers NF, Vandenberghe R, Rascovsky K, Patterson K, Miller BL, Knopman DS, Hodges JR, Mesulam MM, Grossman M: Classification of primary progressive aphasia and its variants. Neurology 2011;76: 1006-1014.

- 3 Hodges JR, Miller B: The classification, genetics and neuropathology of frontotemporal dementia. Introduction to the special topic papers: Part I. Neurocase 2001;7:31-35.

4 Mendez MF, Cummings JL: Dementia: A Clinical Approach, ed 3. Philadelphia, Butterworth-Heinemann, 2003.

- 5 Davies RR, Halliday GM, Xuereb JH, Kril JJ, Hodges JR: The neural basis of semantic memory: evidence from semantic dementia. Neurobiol Aging 2009;30:2043-2052.

6 Kril JJ, Halliday GM: Pathological staging of frontotemporal lobar degeneration. J Mol Neurosci 2011;45:379383.

7 Grossman M: Biomarkers in frontotemporal lobar degeneration. Curr Opin Neurol 2010;23:643-648.

- 8 Gorno-Tempini ML, Dronkers NF, Rankin KP, Ogar JM, Phengrasamy L, Rosen HJ, Johnson JK, Weiner MW, Miller BL: Cognition and anatomy in three variants of primary progressive aphasia. Ann Neurol 2004;55: 335-346.

9 Peelle JE, Troiani V, Gee J, Moore P, McMillan C, Vesely L, Grossman M: Sentence comprehension and voxelbased morphometry in progressive nonfluent aphasia, semantic dementia, and nonaphasic frontotemporal dementia. J Neurolinguistics 2008;21:418-432.

10 Cardenas VA, Boxer AL, Chao LL, Gorno-Tempini ML, Miller BL, Weiner MW, Studholme C: Deformationbased morphometry reveals brain atrophy in frontotemporal dementia. Arch Neurol 2007;64:873-877. 
11 Pan PL, Song W, Yang J, Huang R, Chen K, Gong QY, Zhong JG, Shi HC, Shang HF: Gray matter atrophy in behavioral variant frontotemporal dementia: a meta-analysis of voxel-based morphometry studies. Dement Geriatr Cogn Disord 2012;33:141-148.

$\checkmark 12$ Studholme C, Cardenas V, Blumenfeld R, Schuff N, Rosen HJ, Miller B, Weiner M: Deformation tensor morphometry of semantic dementia with quantitative validation. Neuroimage 2004;21:1387-1398.

13 Mion M, Patterson K, Acosta-Cabronero J, Pengas G, Izquierdo-Garcia D, Hong YT, Fryer TD, Williams GB, Hodges JR, Nestor PJ: What the left and right anterior fusiform gyri tell us about semantic memory. Brain 2010;133:3256-3268.

14 Chan D, Fox NC, Jenkins R, Scahill RI, Crum WR, Rossor MN: Rates of global and regional cerebral atrophy in AD and frontotemporal dementia. Neurology 2001;57:1756-1763.

$\checkmark 15$ Whitwell JL, Anderson VM, Scahill RI, Rossor MN, Fox NC: Longitudinal patterns of regional change on volumetric MRI in frontotemporal lobar degeneration. Dement Geriatr Cogn Disord 2004;17:307-310.

-16 Brambati SM, Rankin KP, Narvid J, Seeley WW, Dean D, Rosen HJ, Miller BL, Ashburner J, Gorno-Tempini ML: Atrophy progression in semantic dementia with asymmetric temporal involvement: a tensor-based morphometry study. Neurobiol Aging 2009;30:103-111.

17 Larsson E, Passant U, Sundgren PC, Englund E, Brun A, Lindgren A, Gustafson L: Magnetic resonance imaging and histopathology in dementia, clinically of frontotemporal type. Dement Geriatr Cogn Disord 2000;11:123-134.

18 Larsson EM, Englund E, Sjobeck M, Latt J, Brockstedt S: MRI with diffusion tensor imaging post-mortem at 3.0 T in a patient with frontotemporal dementia. Dement Geriatr Cogn Disord 2004;17:316-319.

19 Chao LL, Schuff N, Clevenger EM, Mueller SG, Rosen HJ, Gorno-Tempini ML, Kramer JH, Miller BL, Weiner MW: Patterns of white matter atrophy in frontotemporal lobar degeneration. Arch Neurol 2007;64:16191624.

-20 Whitwell JL, Avula R, Senjem ML, Kantarci K, Weigand SD, Samikoglu A, Edmonson HA, Vemuri P, Knopman DS, Boeve BF, Petersen RC, Josephs KA, Jack CR Jr: Gray and white matter water diffusion in the syndromic variants of frontotemporal dementia. Neurology 2010;74:1279-1287.

-21 Zhang Y, Schuff N, Du AT, Rosen HJ, Kramer JH, Gorno-Tempini ML, Miller BL, Weiner MW: White matter damage in frontotemporal dementia and Alzheimer's disease measured by diffusion MRI. Brain 2009;132: 2579-2592.

-22 Matsuo K, Mizuno T, Yamada K, Akazawa K, Kasai T, Kondo M, Mori S, Nishimura T, Nakagawa M: Cerebral white matter damage in frontotemporal dementia assessed by diffusion tensor tractography. Neuroradiology 2008;50:605-611.

23 Borroni B, Brambati SM, Agosti C, Gipponi S, Bellelli G, Gasparotti R, Garibotto V, Di Luca M, Scifo P, Perani D, Padovani A: Evidence of white matter changes on diffusion tensor imaging in frontotemporal dementia. Arch Neurol 2007;64:246-251.

24 Chia LS, Thompson JE, Moscarello MA: Changes in lipid phase behaviour in human myelin during maturation and aging. FEBS 1983;157:155-158.

25 Kemper T: Neuroanatomical and neuropathological changes during aging and dementia; in Albert M, Knoefel J (eds): Clinical Neurology of Aging, ed 2 New York, Oxford University Press, 1994, pp. 3-67.

-26 Marner L, Nyengaard JR, Tang Y, Pakkenberg B: Marked loss of myelinated nerve fibers in the human brain with age. J Comp Neurol 2003;462:144-152.

27 Tang Y, Nyengaard JR, Pakkenberg B, Gundersen HJ: Age-induced white matter changes in the human brain: a stereological investigation. Neurobiol Aging 1997;18:609-615.

-28 Stadlbauer A, Salomonowitz E, Strunk G, Hammen T, Ganslandt O: Age-related degradation in the central nervous system: assessment with diffusion-tensor imaging and quantitative fiber track. Radiology 2008;247:179-188.

-29 Flechsig P: Developmental (myelogenetic) localisation of the cerebral cortex in the human subject. Lancet 1901;158:1027-1029.

-30 Brambati SM, Renda NC, Rankin KP, Rosen HJ, Seeley WW, Ashburner J, Weiner MW, Miller BL, GornoTempini ML: A tensor based morphometry study of longitudinal gray matter contraction in FTD. Neuroimage 2007;35:998-1003.

31 Ashburner J, Friston KJ: Morphometry; in Frackowiak RSJ, Friston KJ, Frith CD, Dolan RJ, Price CJ, Zeki S, Ashburner J, Penny W (eds): Human Brain Function. London, Elsevier, 2004, pp 707-722.

-32 Hua X, Leow AD, Lee S, Klunder AD, Toga AW, Lepore N, Chou YY, Brun C, Chiang MC, Barysheva M, Jack CR Jr, Bernstein MA, Britson PJ, Ward CP, Whitwell JL, Borowski B, Fleisher AS, Fox NC, Boyes RG, Barnes J, Harvey D, Kornak J, Schuff N, Boreta L, Alexander GE, Weiner MW, Thompson PM, Alzheimer's Disease Neuroimaging Initiative: 3D characterization of brain atrophy in Alzheimer's disease and mild cognitive impairment using tensor-based morphometry. Neuroimage 2008;41:19-34.

33 Leow AD, Yanovsky I, Parikshak N, Hua X, Lee S, Toga AW, Jack CR Jr, Bernstein MA, Britson PJ, Gunter JL, Ward CP, Borowski B, Shaw LM, Trojanowski JQ, Fleisher AS, Harvey D, Kornak J, Schuff N, Alexander GE, Weiner MW, Thompson PM: Alzheimer's disease neuroimaging initiative: a one-year follow-up study using tensor-based morphometry correlating degenerative rates, biomarkers and cognition. Neuroimage 2009;45:645-655. 
Lu et al.: Patterns of Brain Atrophy in Clinical Variants of FTLD

-34 Lu PH, Thompson PM, Leow A, Lee GJ, Lee A, Yanovsky I, Parikshak N, Khoo T, Wu S, Geschwind D, Bartzokis G: Apolipoprotein E genotype is associated with temporal and hippocampal atrophy rates in healthy elderly adults: a tensor-based morphometry study. J Alzheimers Dis 2011;23:433-442.

-35 Lee GJ, Lu PH, Hua X, Lee S, Wu S, Nguyen K, Teng E, Leow AD, Jack CR Jr, Toga AW, Weiner MW, Bartzokis G, Thompson PM: Depressive symptoms in mild cognitive impairment predict greater atrophy in Alzheimer's disease-related regions. Biol Psychiatry 2012;71:814-821.

-36 Knopman DS, Jack CR Jr, Kramer JH, Boeve BF, Caselli RJ, Graff-Radford NR, Mendez MF, Miller BL, Mercaldo ND: Brain and ventricular volumetric changes in frontotemporal lobar degeneration over 1 year. Neurology 2009;72:1843-1849.

-37 Knopman DS, Kramer JH, Boeve BF, Caselli RJ, Graff-Radford NR, Mendez MF, Miller BL, Mercaldo N: Development of methodology for conducting clinical trials in frontotemporal lobar degeneration. Brain 2008;131: 2957-2968.

-38 Shattuck DW, Leahy RM: Brainsuite: an automated cortical surface identification tool. Med Image Anal 2002;6:129-142.

39 Sled JG, Zijdenbos AP, Evans AC: A nonparametric method for automatic correction of intensity nonuniformity in MRI data. IEEE Trans Med Imaging 1998;17:87-97.

40 Mazziotta J, Toga A, Evans A, Fox P, Lancaster J, Zilles K, Woods R, Paus T, Simpson G, Pike B, Holmes C, Collins L, Thompson P, MacDonald D, Iacoboni M, Schormann T, Amunts K, Palomero-Gallagher N, Geyer S, Parsons L, Narr K, Kabani N, Le Goualher G, Boomsma D, Cannon T, Kawashima R, Mazoyer B: A probabilistic atlas and reference system for the human brain: International Consortium for Brain Mapping (ICBM). Philos Trans R Soc Lond B Biol Sci 2001;356:1293-322.

-41 Leow AD, Yanovsky I, Chiang MC, Lee AD, Klunder AD, Lu A, Becker JT, Davis SW, Toga AW, Thompson PM: Statistical properties of Jacobian maps and the realization of unbiased large-deformation nonlinear image registration. IEEE Trans Med Imaging 2007;26:822-832.

-42 Hua X, Leow AD, Parikshak N, Lee S, Chiang MC, Toga AW, Jack CR Jr, Weiner MW, Thompson PM: Tensorbased morphometry as a neuroimaging biomarker for Alzheimer's disease: an MRI study of 676 AD, MCI, and normal subjects. Neuroimage 2008;43:458-469.

43 Morris JC: The Clinical Dementia Rating (CDR): current version and scoring rules. Neurology 1993;43:24122414.

$\$ 44$ Cummings JL, Mega M, Gray K, Rosenberg-Thompson S, Carusi DA, Gornbein J: The Neuropsychiatric Inventory: comprehensive assessment of psychopathology in dementia. Neurology 1994;44:2308-2314.

-45 Kertesz A, Davidson W, Fox H: Frontal Behavioral Inventory: diagnostic criteria for frontal lobe dementia. Can J Neurol Sci 1997;24:29-36.

-46 Folstein MF, Folstein SE, McHugh PR: 'Mini-mental state'. A practical method for grading the cognitive state of patients for the clinician. J Psychiatr Res 1975;12:189-198.

47 Delis DC, Kramer JH, Kaplan E, Ober BA: California Verbal Learning Test, ed 2. San Antonio, Psychological Corp, 2000.

48 Wechsler D: Wechsler Memory Scale, Revised: Administration and Scoring Manual. San Antonio, Psychological Corp, 1981.

-49 Mohs RC, Knopman D, Petersen RC, Ferris SH, Ernesto C, Grundman M, Sano M, Bieliauskas L, Geldmacher D, Clark C, Thal LJ: Development of cognitive instruments for use in clinical trials of antidementia drugs: additions to the Alzheimer's Disease Assessment Scale that broaden its scope. The Alzheimer's Disease Cooperative Study. Alzheimer Dis Assoc Disord 1997;11(suppl 2)S13-S21.

50 Golden C: Stroop Experimental Uses. Chicago, Stoelting, 1978.

51 Benton AL, Hamsher KD: Multilingual Aphasia Examination. Iowa City, AJA Associated, 1989.

52 Kaplan E, Goodglass H, Weintraub S: The Boston Naming Test, ed 2. Boston, Lea \& Fabiger, 1978.

53 Bullmore ET, Suckling J, Overmeyer S, Rabe-Hesketh S, Taylor E, Brammer MJ: Global, voxel, and cluster tests, by theory and permutation, for a difference between two groups of structural MR images of the brain. IEEE Trans Med Imaging 1999;18:32-42.

54 Nichols TE, Holmes AP: Nonparametric permutation tests for functional neuroimaging: a primer with examples. Hum Brain Mapp 2002;15:1-25.

55 Thompson PM, Hayashi KM, de Zubicaray G, Janke AL, Rose SE, Semple J, Herman D, Hong MS, Dittmer SS, Doddrell DM, Toga AW: Dynamics of gray matter loss in Alzheimer's disease. J Neurosci 2003;23:9941005.

56 Chiang MC, Reiss AL, Lee AD, Bellugi U, Galaburda AM, Korenberg JR, Mills DL, Toga AW, Thompson PM: 3D pattern of brain abnormalities in Williams syndrome visualized using tensor-based morphometry. Neuroimage 2007;36:1096-1109.

57 Broe M, Hodges JR, Schofield E, Shepherd CE, Kril JJ, Halliday GM: Staging disease severity in pathologically confirmed cases of frontotemporal dementia. Neurology 2003;60:1005-1011.

58 Schofield E, Kersaitis C, Shepherd CE, Kril JJ, Halliday GM: Severity of gliosis in Pick's disease and frontotemporal lobar degeneration: tau-positive glia differentiate these disorders. Brain 2003;126:827-840.

59 Bartzokis G: Age-related myelin breakdown: a developmental model of cognitive decline and Alzheimer's disease. Neurobiol Aging 2004;25:5-18.

60 Bartzokis G: Alzheimer's disease as homeostatic responses to age-related myelin breakdown. Neurobiol Aging 2011;32:1341-1371. 
Lu et al.: Patterns of Brain Atrophy in Clinical Variants of FTLD

61 Gorno-Tempini ML, Dronkers NF, Rankin KP, Ogar JM, Phengrasamy L, Rosen HJ, Johnson JK, Weiner MW, Miller BL: Cognition and anatomy in three variants of primary progressive aphasia. Ann Neurol 2004;55: 335-346.

62 Grossman M: Biomarkers in frontotemporal lobar degeneration. Curr Opin Neurol 2010;23:643-648.

63 Greene JD, Patterson K, Xuereb J, Hodges JR: Alzheimer disease and nonfluent progressive aphasia. Arch Neurol 1996;53:1072-1078.

-64 Grossman M, Xie SX, Libon DJ, Wang X, Massimo L, Moore P, Vesely L, Berkowitz R, Chatterjee A, Coslett HB, Hurtig HI, Forman MS, Lee VM, Trojanowski JQ: Longitudinal decline in autopsy-defined frontotemporal lobar degeneration. Neurology 2008;70:2036-2045.

-65 Knopman DS, Boeve BF, Parisi JE, Dickson DW, Smith GE, Ivnik RJ, Josephs KA, Petersen RC: Antemortem diagnosis of frontotemporal lobar degeneration. Ann Neurol 2005;57:480-488.

66 Kertesz A, McMonagle P, Blair M, Davidson W, Munoz DG: The evolution and pathology of frontotemporal dementia. Brain 2005;128:1996-2005.

67 Knibb JA, Xuereb JH, Patterson K, Hodges JR: Clinical and pathological characterization of progressive aphasia. Ann Neurol 2006;59:156-165.

68 Mesulam M, Wicklund A, Johnson N, Rogalski E, Leger GC, Rademaker A, Weintraub S, Bigio EH: Alzheimer and frontotemporal pathology in subsets of primary progressive aphasia. Ann Neurol 2008;63:709-719.

69 Mesulam M: Primary progressive aphasia pathology. Ann Neurol 2008;63:124-125.

70 Josephs KA, Whitwell JL, Duffy JR, Vanvoorst WA, Strand EA, Hu WT, Boeve BF, Graff-Radford NR, Parisi JE, Knopman DS, Dickson DW, Jack CR Jr, Petersen RC: Progressive aphasia secondary to Alzheimer disease versus FTLD pathology. Neurology 2008;70:25-34. 